\title{
Experimental evidence for a new transmission route in a parasitic mite and its mucus-dependent orientation towards the host snail
}

\author{
H. U. SCHÜPBACH* and B. BAUR \\ Department of Environmental Sciences, Section of Conservation Biology, University of Basel, St Fohanns-Vorstadt 10, \\ CH-4056 Basel, Switzerland
}

(Received 26 Fune 2008; revised 5 August 2008; accepted 25 August 2008)

S UMMAR Y

The route of transmission and host finding behaviour are fundamental components of a parasite's fitness. Riccardoella limacum, a haematophagous mite, lives in the mantle cavity of helicid land snails. To date it has been assumed that this parasitic mite is transmitted during courtship and mating of the host. Here we present experimental evidence for a new transmission route in the host snail Arianta arbustorum. Parasite-free snails were kept on soil on which previously infected host snails had been maintained for 6 weeks. R. limacum was successfully transmitted via soil without physical contact among hosts in 10 out of $22(45 \cdot 5 \%)$ cases. In a series of experiments we also examined the off-host locomotion of $R$. limacum on snail mucus and control substrates using an automated camera system. Parasitic mites showed a preference to move on fresh mucus. Our results support the hypothesis that $R$. limacum uses mucus trails to locate new hosts. These findings should be considered in commercial snail farming and when examining the epidemiology of wild populations.

Key words: parasite transmission, host-finding, snail mucus, Arianta arbustorum, Riccardoella limacum.

\section{INTRODUCTION}

Parasite transmission in a host population is a fundamental component of the parasite's fitness (Fenton et al. 2002; Galvani, 2003), and is closely linked to other traits such as fecundity, survival and virulence (Bull, 1994; Ebert and Herre, 1996; Crossan et al. 2007). In macroparasites, the transmission between hosts is often actively occurring during host contact or through mobile, free-living stages of the parasite (Combes, 2001). Since suitable hosts are patchily distributed in space and time, the optimal strategy for transmission depends on both the mechanisms of parasite transmission (Fenton and Rands, 2004; Robb and Forbes, 2005) and on the spatial structure of the host population (Boots and Mealor, 2007; Crossan et al. 2007). Differences in mechanisms of transmission and pathogenesis may lead to pronounced differences in the epidemiology of the interacting species (Ganusov and Antia, 2003; Frank and Schmid-Hempel, 2008). Strong selection pressure on parasites to develop optimal strategies in order to maximize their likelihood of successful transmission may therefore be expected (Fenton and Rands, 2004; Poulin, 2007). A possible strategy to increase the probability of transmission and to locate new hosts is the use of signals from the environment

\footnotetext{
* Corresponding author: Tel: +416126708 44. Fax: +416126708 32. E-mail: H.Schuepbach@unibas.ch
}

or from the host (Rea and Irwin, 1994; Krasnov et al. 2002; Hertel et al. 2006).

The mite Riccardoella limacum (ScHRANk 1776) is a monoxenous ectoparasite of land snails (Fain and Van Goethem, 1986). The parasite feeds on blood in the mantle cavity of its host. Heavy infestation with $R$. limacum reduces the growth rate and delays reproductive development in the snail Cornu aspersum (MüLler 1774). These adverse effects can seriously influence the economy of commercial snail farming (Graham, 1994; Graham et al. 1996). In the land snail Arianta arbustorum (Linnaeus 1758), R. limacum reduced both the reproductive output and winter survival of its host (Schüpbach and Baur, 2008). However, little is known about the transmission biology of the parasitic mite. The mite is actively transmitted during courtship and mating of the host A. arbustorum. Mites leave the mantle cavity, move over the soft body of the snail, and switch to the new host. However, mites have also been observed in juvenile snails (Baur and Baur, 2005), suggesting other ways of parasite transmission. Individuals of $R$. limacum might also disperse via soil. Daily movements and dispersal of $A$. arbustorum are restricted to a rather narrow range (Baur, 1986; Baur and Baur, 1993). This may enhance the parasite's probability to locate new hosts. Furthermore, snails secrete mucus during locomotion. The adhesive and lubricant characteristics of mucus permit adhesion to the substrate and snail locomotion (Barker, 2001). 
Mucus is also important for the communication among snails. Mucus trails could be used by R. limacum to find new hosts.

The aim of our study was to investigate the transmission biology of $R$. limacum. We experimentally tested whether R. limacum is successfully transmitted via soil without physical contact among host individuals. We also examined the off-host locomotion of $R$. limacum. In particular, we tested whether locomotion of $R$. limacum is affected by mucus trails of the host.

\section{MATERIALS AND METHODS}

\section{Study species}

Riccardoella limacum is a parasitic mite that lives in the mantle cavity of helicid land snails (Fain and Van Goethem, 1986; Graham et al. 1993). The parasite's life cycle has been studied under laboratory conditions in the host snail Cornu aspersum (Graham, 1994). Female mites lay their eggs in the respiratory tissue of their host. Three nymphal mite stages are followed by sexually mature males and females, both $0.4 \mathrm{~mm}$ in body length (Baker, 1970a). The total life cycle of $R$. limacum lasts 19-23 days at temperatures of $20-25{ }^{\circ} \mathrm{C}$. During hibernation of the host, adult mites rarely survive in the mantle cavity, but a new generation of larvae emerges from overwintered eggs in spring. $R$. limacum is a blood-sucking parasite (Baker, 1970b), which causes considerable harm in $C$. aspersum by reducing the activity and the growth rate and delaying reproductive development (Graham et al. 1996).

Arianta arbustorum, a common host of $R$. limacum, is a simultaneously hermaphroditic helicid land snail common in moist habitats of northwestern and central Europe (Kerney and Cameron, 1979). The snail has determinate growth (shell breadth of adults 16-24 mm). Individuals become sexually mature at an age of 2-4 years and live for another 3-4 years (Baur and Raboud, 1988). Individuals usually reproduce through outcrossing. Mating includes elaborate courtship and lasts 2-18 h (Baur, 1992).

A considerable variation in prevalence and intensity of $R$. limacum infection was found in wild A. arbustorum populations in Switzerland (Baur and Baur, 2005). The parasite occurred in 4 out of 11 populations examined, with a prevalence of $45 \cdot 8-77 \cdot 8 \%$. The infection with $R$. limacum affects the life-history and behaviour of $A$. arbustorum (Schüpbach and Baur, 2008). Infected hosts laid fewer eggs and were less active. Furthermore, in 2 out of 3 populations and in experimentally infected snails, hosts suffered an increased mortality during hibernation compared to uninfected snails.

During the long-lasting mating of host snails, $R$. limacum moves from parasite-infected snails to the mating partner $(H$. U. Schüpbach, personal observation). However, mite infection sporadically occurs in juvenile snails (Baur and Baur, 2005), suggesting other types of parasite transmission.

\section{Experiment 1: Parasite transmission}

We collected 22 mite-infected snails (hereafter referred to as infected snails) in Nuglar $\left(47^{\circ} 29^{\prime} \mathrm{N}\right.$, $7^{\circ} 42^{\prime} \mathrm{E}$; elevation $430 \mathrm{~m}$ ), and 24 snails in a parasitefree population near Gurnigelbad $\left(46^{\circ} 45^{\prime} \mathrm{N}, 7^{\circ} 27^{\prime} \mathrm{E}\right.$; elevation $1330 \mathrm{~m}$ ), in Switzerland. The snails were kept individually in transparent plastic beakers $(6.5 \mathrm{~cm}$ in diameter, $8 \mathrm{~cm}$ deep) on moist soil mixed with powdered limestone under a light: dark regime of $16: 8 \mathrm{~h}$ and a constant temperature of $19 \pm 1{ }^{\circ} \mathrm{C}$. The soil was obtained from the locality Gurnigelbad where R. limacum may not occur (Baur and Baur, 2005). The beakers were cleaned 1-2 times per week and a diet of fresh lettuce was provided ad libitum. To test whether the transmission of $R$. limacum can occur without physical contact of hosts, the infected snails were removed from the beakers after 6 weeks and replaced by parasite-free snails (hereafter referred to as test snails) from the Gurnigelbad population $(n=46)$. Test snails were checked for mites after being kept for 6 weeks in the beakers of the infected snails.

The infection status and intensity of infection of both the infected and test snails were assessed using a non-invasive screening method (Baur and Baur, 2005). The soft body and respiratory pore of each individual were carefully examined for mites using a magnifying glass $(10 \times)$. Mite screening was repeated 3 times on different days. A snail was considered as parasite-infected if at least 1 mite could be detected in 3 observations. The intensity of infection was expressed as the mean number of mites observed in the 3 examinations (Baur and Baur, 2005).

\section{Experiments 2-4: Mite locomotion}

General method. We applied an automated camera system to examine whether the off-host locomotion of $R$. limacum is affected by the presence of snail mucus. We used a template with a round hole in the centre $(5.4 \mathrm{~mm}$ in diameter) to coat a defined area of a microscope slide with fresh mucus (Fig. 1). After removing the template we placed a mite in the centre of the mucus spot. Mites were transferred with a small, moistened paintbrush from the soft body of infected snails collected in Nuglar (see above). Fresh mucus was obtained from the same snail from which the mite was collected. Immediately after transfer, the movement of the mite was recorded with a digital camera (Canon PowerShot S70) mounted on a stereomicroscope. We took 15 photographs with a frame of $1 \mathrm{sec}$. The photographs were analysed using the image processing software Image (NIH, USA; 


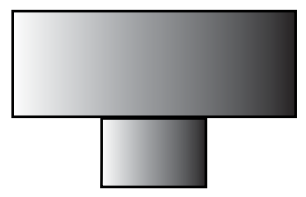

Camera

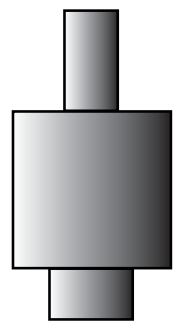

Binocular

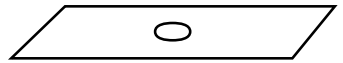

Microscope slide

Fig. 1. Assay for studying movement patterns of Riccardoella limacum. Mite movement on microscope slide $(76 \times 26 \mathrm{~mm})$ was photographed at 1 -sec intervals Treatments were applied in the central area (diameter $5.4 \mathrm{~mm}$ ) of microscope slides.

Version 1.36b; http://rsb.info.nih.gov/ij/). We used the template to mark the central area of the microscope slide, and recorded the locomotion of the mite on the photographs. For each mite we calculated the proportion of photographs (out of 15) on which the mite stayed within the defined central area. We also measured the distance moved by the mite between 2 consecutive photographs.

\section{Experiment 2: Mite locomotion on fresh mucus}

We used the automated camera system to examine whether mite locomotion is influenced by fresh snail mucus or dry mucus. We covered the central area of the microscope slides with fresh mucus in the first treatment and with dry mucus in the second treatment. Blank microscope slides were used as control. Twenty-two individual mites were tested in each treatment and control, and the percentage of photographs on which the mite stayed in the central area was assessed for each mite (see general method).

\section{Experiment 3: Humidity and mite locomotion}

Mite locomotion on fresh mucus could be a result of the humidity of this substrate rather than other characteristics of snail mucus. To distinguish between these two alternatives, we covered the microscope slides with a thin paper towel (KimberleyClark, Precision Wipes) moistened with $90 \mu 1$ of water before two treatments were prepared. Then 17 mites were tested twice on slides with a mucus spot in the central area (treatment 1) and on moist slides without mucus (control). The sequence in which individual mites were tested was alternated between the treatments. Data recording was as described above.

\section{Experiment 4: Movement patterns of mites}

We also examined whether the locomotion patterns of mites on fresh mucus differs from that on a moist surface. Two aspects of locomotion were considered (i) the distance moved per time unit by a mite and (ii) the directedness of locomotion. We covered the microscope slides with moistened paper towel (see Exp. 3). In contrast to Exp. 3, however, the entire slide was covered with fresh mucus (treatment). As the control we used slides covered with moistened paper towel. A total of 16 mites were tested on both substrates (alternating sequences). Using series of 15 photographs made at 1 -sec intervals we measured the distance moved by each mite between 2 consecutive photographs and calculated the mean distance covered per sec for each mite. Furthermore, we measured the angles between the directions of the movement between 2 consecutive photographs. If the movement of a mite is directed, then the distribution of angles between 2 consecutive 1 -sec steps will vary around $180^{\circ}$. If mite movement is random, then the distribution of angles between consecutive steps will follow a uniform distribution. To compare mite locomotion on different substrates, the mean angle and the resultant mean vector were calculated for each test series (Batschelet, 1981).

\section{Statistical analysis}

Data analysis was performed using R Statistical Software (R Development Core Team, 2008). We used chi-square tests (Exp. 2) and repeated measure ANOVA models (Exp. 3) to compare the proportions of photographs on which the mite stayed in the central area. In Exp. 4, we used Rayleigh tests to evaluate the directedness of angular data (Batschelet, 1981). Means \pm s.E. are reported.

\section{RESULTS}

\section{Experiment 1: Parasite transmission}

Parasitic mites can be transmitted via soil. Ten out of 22 originally parasite-free snails $(45 \cdot 5 \%)$ were infected after being maintained for 6 weeks on soil on which parasite-infected snails were previously kept. The mean intensity of infection was $1 \cdot 32 \pm 0 \cdot 22$ mites in the originally infected snails and $3 \cdot 20 \pm 0 \cdot 76$ mites in the newly infected test snails. The mite-intensity of originally infected snails and those of infected test snails kept later in the same beakers were not correlated (Pearson's correlation: $r=-0 \cdot 27, n=10$, $P=0 \cdot 453$ ). As expected, no mite transmission occurred from soil of uninfected snails to test snails $(n=24)$. 


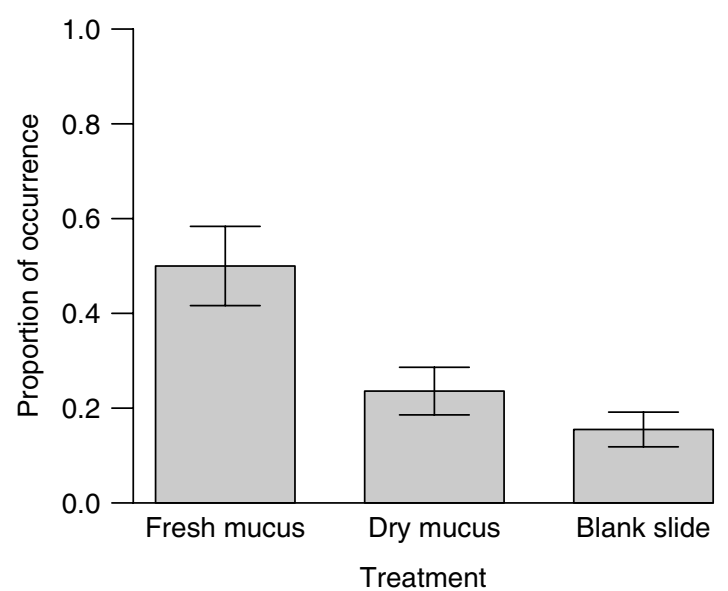

Fig. 2. Proportion of photographs (means \pm 1 s.e.) where mites stayed within the defined central area of microscope slides provided with fresh mucus, dry mucus and on blank microscope slides.

\section{Experiment 2: Mite locomotion on fresh mucus}

Fresh mucus appears to affect parasite locomotion. The proportion of photographs on which the mite stayed within the defined area was $0.50 \pm 0.08$ on slides with fresh mucus, $0 \cdot 23 \pm 0 \cdot 05$ on slides with dry mucus and $0 \cdot 16 \pm 0 \cdot 04$ on blank slides (Fig. 2). The difference was significant between fresh mucus and dry mucus $\left(\chi^{2}=5 \cdot 12\right.$, D.F. $\left.=1, P=0.024\right)$ and between fresh mucus and blank slides $\left(\chi^{2}=8 \cdot 33\right.$, D.F. $=1, P=0 \cdot 004)$. However, there was no difference in mite locomotion between slides with dry mucus and blank slides $\left(\chi^{2}=1 \cdot 17\right.$, D.F. $=1, P=$ $0 \cdot 279)$.

\section{Experiment 3: Humidity and mite locomotion}

The mean proportion of photographs where the mite stayed within the defined central area was significantly higher on microscope slides provided with fresh mucus $(0 \cdot 48 \pm 0 \cdot 09)$ than on moist slides without mucus $\left(0 \cdot 24 \pm 0 \cdot 07 ; \quad F_{1,15}=14 \cdot 41, \quad P=0 \cdot 002\right)$. This indicates that $R$. limacum shows a preference for fresh mucus as a substrate for locomotion. However, there was a significant interaction between the test sequence and the main effect (Fig. $3 ; \mathrm{F}_{1,15}=8 \cdot 91$, $P=0 \cdot 009)$.

\section{Experiment 4: Movement patterns of mites}

Individual mites $(n=16)$ did not differ in the mean distance moved on slides covered by fresh mucus $(0.93 \pm 0.11 \mathrm{~mm})$ and on slides covered by moist paper towel $\left(1 \cdot 05 \pm 0.09 \mathrm{~mm} ; \mathrm{F}_{1,14}=1 \cdot 62, P=0 \cdot 224\right)$. Furthermore, the interaction between mean distance moved and treatment sequence was not significant $\left(\mathrm{F}_{1,15}=1 \cdot 07, P=0 \cdot 319\right)$. On snail mucus, random movement patterns (Rayleigh test: $P>0 \cdot 05$ ) were

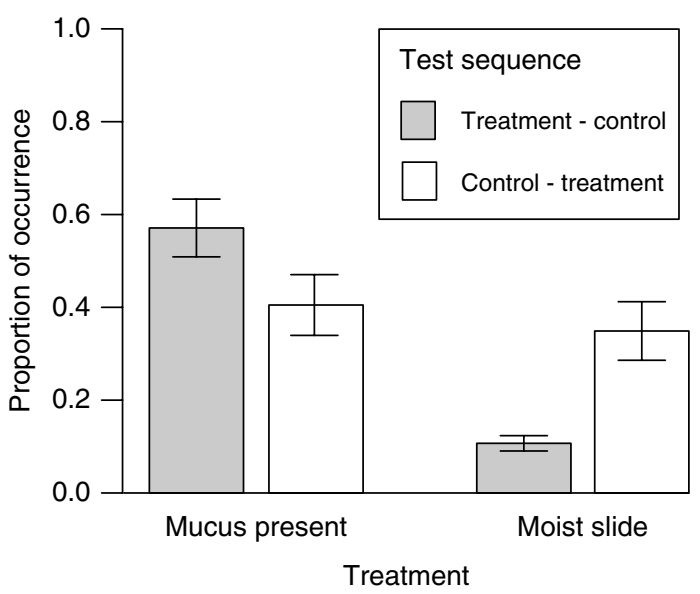

Fig. 3. Proportion of photographs (means \pm 1 s.E.) where mites stayed within the defined central area on moistened surfaces provided with fresh mucus or without mucus. Each mite $(n=17)$ was tested in both treatments with alternating test sequences. The mites showed a preference for fresh mucus as a substrate for locomotion, but there was a significant interaction between treatment and the test sequence.

recorded in 3 mites $(18.75 \%)$, and directed movements (Rayleigh test: $P<0 \cdot 05)$ in 13 mites $(81 \cdot 25 \%)$. Similarly, on moist paper towel, random movement patterns were found in 4 mites $(25 \%)$, and directed movements in 12 mites $(75 \%)$. The two substrates did not differ in the proportions of mites moving in a random pattern or in a directed way (chi-square test: $\chi^{2}=0 \cdot 18$, D.F. $\left.=1, P=0 \cdot 669\right)$.

\section{ISCUSSION}

Our study provides experimental evidence that $R$. limacum can be transmitted via soil without physical contact between hosts. Furthermore, R. limacum showed a preference to move on fresh snail mucus in the experiment.

$R$. limacum depends on its host to complete the life cycle. Food uptake and reproduction are only possible in the mantle cavity of the host. Baker (1970a) studied the life cycle and off-host survival of R. limacum. Mites kept in culture cells survived for 8 days without food supply at room temperature. In our first experiment, parasite transmission occurred by mites that had temporarily left their host and stayed in the soil. It is, however, not known how long parasitic mites can survive in the soil. In our experiment, the intensity of the mite infection was higher in newly infected test snails compared to snails that transmitted the infection. Test snails might be more susceptible to mite infection because they were collected in a parasite-free population and thus were never exposed to R. limacum. However, the high intensity of the mite infection found in test snails suggests that several mites have been transmitted and that they successfully established a new parasite cohort. 
Dissections of host snails revealed that the actual number of mites in the mantle cavity of $A$. arbustorum was about 10 times higher than the mite intensity estimated with the non-invasive method (Baur and Baur, 2005).

The hypothesis that mites of the genus Riccardoella follow mucus trails to locate host snails was first proposed by Turk and Phillips (1946) who observed that mites which temporarily left the host relocated them with high reliability. Our experiments provide evidence that $R$. limacum uses fresh mucus as a cue for their movements. Since individuals of Riccardoella are blind, visual orientation can be excluded as the interpretation of our findings (Fain and Van Goethem, 1986). Furthermore, as shown in Exp. 4, the preference for moving on fresh mucus is not an artefact caused by a different speed and/or directedness of mite movement. Most probably the chemical composition of mucus serves as a cue for $R$. limacum. Our experiment revealed a significant interaction between the substrate and the sequence of the treatment. The effect of the treatment was stronger when mites were first tested on slides containing fresh mucus. Mites removed from host snails and immediately tested may behave differently than mites that were temporarily stored on moist paper towel. Stress could partly explain this difference in locomotory behaviour.

Our experiments showed that the locomotion of $R$. limacum is influenced by the presence of fresh mucus. There was, however, no difference in the mite's movement behaviour on slides covered with dry mucus and on blank control slides. Mucus is widely used as a source of information among snails. Snails use mucus trails to locate mating partners and to discriminate between conspecific and heterospecific individuals (Shaheen et al. 2005). Parasites may also use cues from snail mucus. Our experiments were not designed to examine the importance of mucus-oriented mite locomotion in the field. It remains unclear on which spatial scale snail mucus is used to locate new hosts. However, our findings reject previous statements considering $R$. limacum as an exclusively sexually transmitted parasite.

Mechanisms of transmission strongly influence the interaction between the host and parasite populations (Fenton et al. 2002). Our results showed that R. limacum can be transmitted among hosts via soil. Furthermore, we demonstrated that $R$. limacum uses fresh mucus as a cue for locomotion. The findings support the hypothesis that $R$. limacum follows mucus trails to locate new hosts. The transmission of $R$. limacum via soil should be considered in commercial snail farming and when examining the epidemiology of wild snail populations.

We thank A. Baur and two anonymous referees for valuable comments on the manuscript. Financial support was received from the Swiss National Science Foundation (grant 31-110061).
REFERENCES

Baker, R. A. $(1970 a)$. Studies on the life history of Riccardoella limacum (Schrank) (Acari, Trombidiformes). Fournal of Natural History $\mathbf{4}$, 511-519.

Baker, R. A. $(1970 \mathrm{~b})$. The food of Riccardoella limacum (Schrank) (Acari, Trombidiformes) and its relationship with pulmonate molluscs. Fournal of Natural History $\mathbf{4}$, 521-530.

Barker, G. M. (ed.) (2001). The Biology of Terrestrial Molluscs. CABI Publishing, Wallingsford, Oxon., UK.

Batschelet, E. (1981). Circular Statistics in Biology, Academic Press, London.

Baur, A. and Baur, B. (1993). Daily movement patterns and dispersal in the land snail Arianta arbustorum. Malacologia 35, 89-98.

Baur, A. and Baur, B. (2005). Interpopulation variation in the prevalence and intensity of parasitic mite infection in the land snail Arianta arbustorum. Invertebrate Biology 124, 194-201. doi: 10.1111/ j.1744-7410.2005.00019.x.

Baur, B. (1986). Patterns of dispersion, density and dispersal in alpine populations of the land snail Arianta arbustorum (L.) (Helicidae). Holarctic Ecology $\mathbf{9}$, 117-125.

Baur, B. (1992). Random mating by size in the simultaneously hermaphroditic land snail Arianta arbustorum - experiments and an explanation. Animal Behaviour 43, 511-518.

Baur, B. and Raboud, C. (1988). Life-history of the land snail Arianta arbustorum along an altitudinal gradient. Fournal of Animal Ecology 57, 71-87.

Boots, M. and Mealor, M. (2007). Local interactions select for lower pathogen infectivity. Science $\mathbf{3 1 5}$, 1284-1286. doi: 10.1126/science.1137126.

Bull, J. J. (1994). Virulence. Evolution 48, 1423-1437.

Combes, C. (2001). Parasitism: The Ecology and Evolution of Intimate Interactions. The University of Chicago Press, Chicago, USA.

Crossan, J., Paterson, S. and Fenton, A. (2007). Host availability and the evolution of parasite life-history strategies. Evolution 61, 675-684. doi: 10.1111/ j.1558-5646.2007.00057.x.

Ebert, D. and Herre, E. A. (1996). The evolution of parasitic diseases. Parasitology Today 12, 96-101.

Fain, A. and Van Goethem, J. L. (1986). Les acariens du genre Riccardoella Berlese, 1923 parasites du poumon de mollusques gastéropodes pulmonés terrestres. Acarologia 27, 125-140.

Fenton, A., Fairbairn, J. P., Norman, R. and Hudson, P. J. (2002). Parasite transmission: reconciling theory and reality. Fournal of Animal Ecology 71, 893-905.

Fenton, A. and Rands, S. A. (2004). Optimal parasite infection strategies: a state-dependent approach. International Fournal for Parasitology 34, 813-821. doi: 10.1016/j.ijpara.2004.02.003.

Frank, S. A. and Schmid-Hempel, P. (2008). Mechanisms of pathogenesis and the evolution of parasite virulence. Fournal of Evolutionary Biology 21, 396-404. doi: 10.1111/j.1420-9101.2007.01480.x.

Galvani, A. P. (2003). Epidemiology meets evolutionary

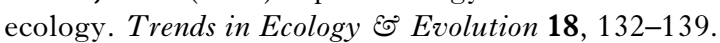


Ganusov, V. V. and Antia, R. (2003). Trade-offs and the evolution of virulence of microparasites: do details matter? Theoretical Population Biology 64, 211-220. doi: 10.1016/S0040-5809(03)00063-7.

Graham, F. J. (1994). The biology and control of Riccardoella limacum (Schrank), a mite pest of farmed snails. PhD thesis. University of Wales, UK.

Graham, F. J., Ford, J. B. and Runham, N. W. (1993). Comparison of two species of mites of the same genus, Riccardoella associated with Molluscs. Acarologia 34, 143-148.

Graham, F. J., Runham, N. W. and Ford, J. B. (1996). Long-term effects of Riccardoella limacum living in the lung of Helix aspersa. British Crop Protection Council Symposium Proceedings 66, 359-364.

Hertel, J., Holweg, A., Haberl, B., Kalbe, M. and Haas, W. (2006). Snail odour-clouds: spreading and contribution to the transmission success of Trichobilharzia ocellata (Trematoda, Digenea) miracidia. Oecologia 147, 173-180. doi: 10.1007/ s00442-005-0239-5.

Kerney, M. and Cameron, R. (1979). A Field Guide to the Land Snails of Britain and North-west Europe, Collins, London, UK.

Krasnov, B. R., Khokhlova, I. S., Oguzoglu, I. and Burdelova, N. V. (2002). Host discrimination by two desert fleas using an odour cue. Animal Behaviour 64, 33-40. doi: 10.1006/anbe.2002.3030.
Poulin, R. (2007). Evolutionary Ecology of Parasites, 2nd Edn. Princeton University Press, Princeton, USA.

R Development Core Team (2008). $R$ : A Language and Environment for Statistical Computing, R Foundation for Statistical Computing. URL http://www.R-project.org, Vienna, Austria.

Rea, J. G. and Irwin, S. W. B. (1994). The ecology of host-finding behaviour and parasite transmission - past and future perspectives. Parasitology 109(Suppl.), S31-S39.

Robb, T. and Forbes, M. R. (2005). Success of ectoparasites: how important is timing of host contact? Biology Letters 1, 118-120. doi: 10.1098/ rsbl.2004.0271.

Schüpbach, H. U. and Baur, B. (2008). Parasitic mites influence fitness components of their host, the land snail Arianta arbustorum. Invertebrate Biology 127, 350-356 doi:10.1111/j.1744-7410.2008.00138.x.

Shaheen, N., Patel, K., Patel, P., Moore, M. and Harrington, M. A. (2005). A predatory snail distinguishes between conspecific and heterospecific snails and trails based on chemical cues in slime. Animal Behaviour 70, 1067-1077. doi: 10.1016/j.anbehav. 2005.02.017

Turk, F. A. and Phillips, S. M. (1946). A monograph of the slug mite - Riccardoella limacum (Schrank). Proceedings of the Zoological Society of London 115, $448-472$. 